\title{
A Comprehensive Study of Silicon Micropillar Based Biporous Evaporator
}

\author{
Mengyao Wei ${ }^{1,2}$, Bin He ${ }^{1}$, Qian Liang ${ }^{1}$, Sivanand Somasundaram ${ }^{1}$, Chuan Seng Tan ${ }^{1,2}$, Evelyn N.Wang ${ }^{1,3}$ \\ ${ }^{1}$ Low Energy Electronic Systems (LEES) IRG, Singapore-MIT Alliance for Research and Technology (SMART) Centre \\ 1 CREATE Way, Singapore 138602 \\ ${ }^{2}$ School of Electrical and Electronics Engineering, Nanyang Technological University \\ 50 Nanyang Avenue, Singapore 639798 \\ ${ }^{3}$ Department of Mechanical Engineering, Massachusetts Institute of Technology \\ 77 Massachusetts Avenue, Cambridge, MA 02139, United States \\ enwang@mit.edu
}

\begin{abstract}
Silicon micropillar based evaporators were proven to be good candidates in advanced vapor chambers, due to their high permeability, excellent capillary performance and ease of control over the fabrication process. In this paper, biporous silicon micropillar based evaporator with microchannels to shorten the fluid transportation distance was studied comprehensively. Semianalytical model in predicting the dryout heat flux of biporous evaporator was developed. Evaporator samples with different microchannel widths were fabricated and tested. Sample with geometries of $d=3.4 \mu \mathrm{m}, h=9.00 \mu \mathrm{m}, l=6 \mu \mathrm{m}, l_{i}=101.0 \mu \mathrm{m}, w=58.5$ $\mu \mathrm{m}$ was able to demonstrate a dryout heat flux $q "=55.9 \mathrm{~W} / \mathrm{cm}^{2}$. This has a difference of only $9.0 \%$ compared to the model predicted dryout heat flux. The biporous evaporator was found to have a gentle drop of heat transfer coefficient after dryout, owing to the existence of microchannels that can shorten the fluid propagation distance. Samples with wider microchannels were found to have larger superheat values, due to the smaller thin film evaporation areas of these sample. This paper provided great insights into the investigation of biporous evaporators and can serve as important design guidance for biporous evaporator utilized in advanced vapor chamber.
\end{abstract}

Keywords: biporous, evaporator, micropillar, dryout heat flux

\section{Introduction}

As predicted by Moore's law, the shrinkage of size and significant increase of electronic device density on integrated chips are inevitable trends for semiconductor industries. As a consequence, the integrated chips will have high power density as well as large heat generation. Performance and reliability of electronic devices significantly depends on their operating temperature, where the failure rate of these devices increases almost exponentially with temperature. Vapor chamber, which is a 2D planar heat pipe, was extensively studied and was proven to be a promising solution for thermal management issues encountered. A vapor chamber utilizes high latent heat phase change process to dissipate heat efficiently with small temperature rise, and it works passively without any external pumping power [1,2]. It is composed of evaporator, condenser, and adiabatic regions with working fluid enclosed inside the chamber. The evaporator section absorbs heat from hotspot and allows phase change to occur. It is the limiting factor that determines the dryout heat flux of a vapor chamber, since the working fluid was transported by the capillary effect in the evaporator. Thus, a vapor chamber can have good heat dissipation capability when the evaporator is optimized.

Types of the evaporator can be divided into sintered powder particles, wire meshes, micro-grooves, and micropillars etc.. Distinguished by their structures, evaporators can be categorized into uniform evaporators with mono pore size and biporous evaporators with two distinguished pore sizes. In a monoporous uniform evaporator, the capillary pressure and permeability are two competing factors for its liquid transportation performance. While a biporous evaporator can decouple these two factors with a small pore size to provide high capillary pressure and large pore size to reduce the flow resistance. Biporous structure was proven to possess higher heat transfer coefficient and dryout heat flux as compared to monoporous evaporators [3]. Sintered powder biporous evaporators were extensively studied. Semenic et. al. [4-7] fabricated a group 
of $\mathrm{Cu}$ sintered powder biporous evaporators with thickness of $1 \sim 3 \mathrm{~mm}$, small pore size of $53 \sim 63 \mu \mathrm{m}$ and large pore size of $500 \sim 710 \mu \mathrm{m}$. It was found that the dryout heat flux of biporous evaporator was geometric dependent which was determined by evaporator thickness, particle size, cluster size etc.. The highest heat flux they could achieve was 990 $\mathrm{W} / \mathrm{cm}^{2}$ at a very high superheat of $147^{\circ} \mathrm{C}$ with $3 \mathrm{~mm}$ thick evaporator, $455 \mu \mathrm{m}$ large pore size and $63 \mu \mathrm{m}$ small pore size. 11 times enhancement in capillary performance on sintered glass powder biporous evaporator with particle size of $40 \sim 600$ $\mu \mathrm{m}$ and cluster size of $250 \sim 1440 \mu \mathrm{m}$ was observed by Byon et. al. [8].

However, sintering temperature and time have a strong influence on the pore size of evaporator, interconnectivity and roughness, and it is difficult to accurately control the sintering process. Micropillar based evaporators possess advantages of high permeability and capillary pressure, accurate control over the evaporator geometries and ease of fabrication through mature Micro-Electro Mechanical Systems (MEMS) process [1, 9-11]. Micropillar evaporator and vapor chamber made of silicon have the advantages of direct integration with electronic devices, elimination of thermal interface resistance, and they also can avoid thermal expansion mismatch between the cooling devices and electronic devices. Thus the silicon micropillar based biporous evaporator with various structures was studied by few research groups. Byon et. al. [12] studied the capillary performance of micropillar evaporators with staggered arrays, squared arrays, diamond arrays and microgroove types. Performance of these biporous structures were compared with monoporous structures. $35 \%$ and $31 \%$ higher capillary performance were observed for groove and square arrays respectively. Capillary performance was found to strongly depend on solid fraction of the evaporator. Ravi et. al. [13] investigated the fluid transportation in in-plane hybrid biporous evaporator and out-of-plane biporous evaporator with a porous mesh suspended over uniform micropillar arrays. Out-of-plane biporous evaporators' dryout performance was found to be profoundly influenced by the mesh thickness. Coso et. al. [14] fabricated evaporators with micropillars separated by microchannels, where the micropillars can provide high capillary performance with microchannels to reduce the overall flow resistance. Evaporator micropillars with diameter of $3 \sim 29 \mu \mathrm{m}$ and microchannels with size of 30/60 $\mu \mathrm{m}$ were prepared. Highest heat transfer coefficient of $20.7 \pm 2.4$ $\mathrm{W} / \mathrm{cm}^{2} \mathrm{~K}$ can be obtained with heat flux of $119.6( \pm 4.2) \mathrm{W} / \mathrm{cm}^{2}$ in thin film evaporation region. A transition between evaporation and nucleate boiling can be observed for some of the samples.

Aforementioned studies on biporous evaporators were performed experimentally. In this paper, a theoretical model was constructed for silicon micropillar based biporous evaporators with microchannels to separate uniform micropillar arrays. Evaporator samples were fabricated by MEMS process. Thermal characterization and parametric studies were done to study the influence of the microchannel width. This paper examined the performance of biporous evaporators systematically and can serve as useful design guidance for evaporators.

\section{Nomenclature}

$L \quad$ Wicking length, $(\mathrm{cm})$

c Solid fraction

$d \quad$ Micropillar diameter, $(\mu m)$

$h \quad$ Micropillar height, $(\mu m)$

$l \quad$ Micropillar pitch (center-to-center distance), $K_{3 D}$ $(\mu m)$

$q$,' Maximum heat flux $\left(\mathrm{W} / \mathrm{cm}^{2}\right)$

rf Roughness factor of micropillar sidewalls, $\pi / 2$

$w \quad$ Half microchannel width, $(\mu m)$

$u \quad$ Flow velocity, $(\mathrm{m} / \mathrm{s})$

$\theta$ Contact angle, ${ }^{\circ}$ )

$\varepsilon \quad$ Porosity

$\sigma \quad$ Surface tension, $(N / m)$

$\mu \quad$ Viscosity, $($ Pa $\cdot s)$
$A_{m} \quad$ Actual meniscus area, $\left(m^{2}\right)$

$A_{p} \quad$ Projected meniscus area, $\left(\mathrm{m}^{2}\right)$

$h_{f g} \quad$ Latent heat of vaporization, $(\mathrm{J} / \mathrm{kg})$

$K_{2 D} \quad$ Permeability of planar post arrays, $\left(\mathrm{m}^{2}\right)$

3D permeability of micropillar wick, $\left(\mathrm{m}^{2}\right)$

$k_{\text {eff }} \quad$ Effective thermal conductivity, $(\mathrm{W} / \mathrm{m} \cdot \mathrm{K})$

$l_{i} \quad$ Half micropillar island width, $(\mu m)$

$P_{c a p} \quad$ Maximum capillary pressure, $(\mathrm{Pa})$

$P_{l a} \quad$ Pressure drop inside microchannel, $(\mathrm{Pa})$

$\rho_{l} \quad$ Liquid density, $\left(\mathrm{kg} / \mathrm{m}^{3}\right)$

$\Delta E \quad$ Surface energy change as liquid fills one unit cell

$\Delta T \quad$ Superheat, $\left({ }^{\circ} \mathrm{C}\right)$

$\Delta V \quad$ Volume of liquid that fills one unit cell 


\section{Model and Optimization}

A schematic illustration of the biporous evaporator is shown in Fig. 1. It has uniformly distributed micropillar arrays (islands) with size $2 l_{i}$ separated by microchannels with size $2 w$. The diameter, height and center-to-center distance of micropillars were denoted as $d, h$ and $l$ respectively. Microchannels serve as liquid reservoirs in supplying fluid to sustain the evaporation in island regions.
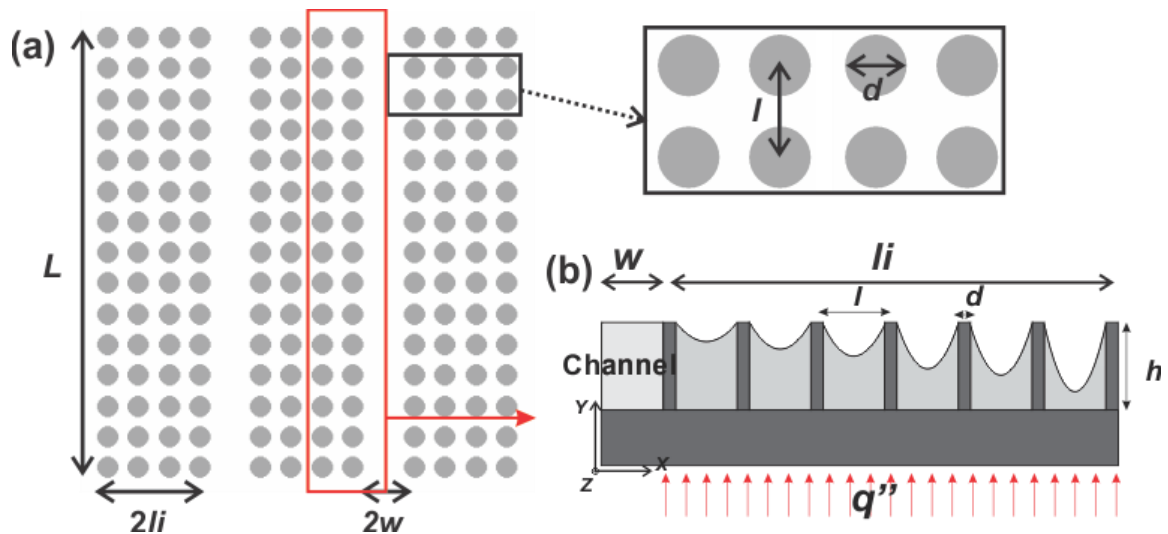

Fig. 1: Schematic illustration of silicon micropillar based biporous evaporator (a) Top view with micropillar geometries of diameter $d$, pitch $h$, island size $2 l_{i}$, microchannel size $2 w$, array length $L$ (b) Cross-sectional view with heat flux $q^{\prime \prime}$ applied at the bottom and microchannel serve as liquid reservoir.

Dryout heat flux of silicon micropillar based biporous evaporator can be expressed as [9]:

$$
q^{\prime \prime}=\frac{\frac{2 \rho_{l} h_{f g} h K}{l_{i} \mu}\left[1-\frac{\tanh \left(\sqrt{\frac{\varepsilon}{K}} h\right)}{\sqrt{\frac{\varepsilon}{K}} h}\right] \frac{1}{l_{i}+w} P_{c a p}}{1+\frac{2 h K}{l_{i}^{2}}\left[1-\frac{\left.\tanh \left(\sqrt{\frac{\varepsilon}{K}} h\right)\right]}{\sqrt{\frac{\varepsilon}{K}} h}\right] \frac{1}{l_{i}+w} \frac{L^{2}}{w h f\left(\frac{w}{l_{i}}, \frac{h}{l_{i}}\right)}}
$$

where $\rho_{l}, h_{f g}$ and $\mu$ are liquid density, latent heat and viscosity respectively, which are physical properties of working fluid. $\varepsilon$ is the porosity of the micropillar arrays. Capillary pressure $P_{c a p}$ is expressed as[15]:

$$
P_{c a p}=\frac{\sigma r f \cos \theta \pi d h+\sigma \cos \theta A_{p}-\sigma A_{m}}{\Delta V}
$$

where $A_{p}, A_{m}$ and $\Delta V$ are geometrically dependent projected meniscus area, actual meniscus area and volume of liquid in micropillar areas respectively. Equation (2) valid for $h / l>1$. Detailed expression of these parameters can be found in [15].

Another important parameter that governs the fluid transportation property of micropillar evaporator is the permeability $K$, which is represented by the following equation [16]: 


$$
K=\frac{h_{e f f}+\frac{\varepsilon d}{4(1-\varepsilon)}}{h+\frac{\varepsilon d}{4(1-\varepsilon)}} \frac{h_{e f f}}{h} K_{2 D}\left[1-\frac{\exp \left(2 \sqrt{\frac{\varepsilon}{K_{2 D}}} h_{e f f}\right)-1}{\sqrt{\frac{\varepsilon}{K_{2 D}}} h_{e f f}\left(\exp \left(2 \sqrt{\frac{\varepsilon}{K_{2 D}}} h_{e f f}\right)+1\right)}\right]
$$

The above equation considered the effect of liquid meniscus. In Equation (3), $K_{2 D}$ denotes the permeability with the assumption of flat meniscus shape, while $h_{\text {eff }}$ is the effective meniscus height by considering the meniscus shape. Expression for $K_{2 D}, h_{\text {eff }}$ can be found in [16]. Equation (3) holds for $d / l<0.57$

Function $f\left(\frac{w}{l_{i}}, \frac{h}{l_{i}}\right)$ is a curve fitted function to account for the pressure drop in microchannels and:

$$
\begin{aligned}
& f\left(\frac{w}{l_{i}}, \frac{h}{l_{i}}\right)=\left[-2.3868 \times 10^{-4}+4.8541 \times 10^{-2} \frac{h}{l_{i}}-1.4325\left(\frac{h}{l_{i}}\right)^{2}\right] \times \exp \left(-\frac{\frac{w}{l_{i}}}{0.11073-0.23438 \frac{h}{l_{i}}+4.57228\left(\frac{h}{l_{i}}\right)^{2}}\right) \\
& +\left[-1.3911 \times 10^{-4}+7.1494 \times 10^{-3} \frac{h}{l_{i}}+0.8331\left(\frac{h}{l_{i}}\right)^{2}\right]
\end{aligned}
$$

Detailed derivation process of $q$ "' can be found in [9]. By substituting Eq. (2) (4) into Eq. (1). The dryout heat flux of biporous evaporators can be evaluated.

\section{Experiments}

\subsection{Sample Fabrication}

Standard Micro-Electro Mechanical Systems (MEMS) fabrication process was adopted to fabricate the biporous evaporator wicks using double polished 6 inch $\mathrm{Si}$ wafers. This was achieved through the growth of $1 \mu \mathrm{m}$ thermal SiO2 onto both sides of the wafer to act as etching mask and insulation layer for the evaporator. The evaporator wicks were created on the front side of the $\mathrm{Si}$ wafer with desired micropillar geometries, islands and microchannel sizes. Photolithography was performed to transfer the evaporator wick patterns onto the wafer while reactive ion etching was conducted to etch away unwanted $\mathrm{SiO} 2$. After that, deep reactive ion etching (DRIE) was conducted to create micropillars with desired height. Size of the micropillar wicks was $1 \mathrm{~cm} \times 1.5 \mathrm{~cm}$. There was an extra $0.5 \mathrm{~cm}$ left on the vertical direction of the evaporator wicks according to Fig. 2(a). This was to account for the $0.27 \mathrm{~mm}$ macroscopic meniscus formed when the evaporator was inserted into the liquid vertically with depth of $0.23 \mathrm{~mm}$. Thus the total area for evaporation was $1 \mathrm{~cm} \times 1 \mathrm{~cm}$. Structure of biporous evaporator was uniformly distributed micropillar arrays with width of 2li, separated by microchannels with size of $2 \mathrm{w}$ according to Fig. 2(b). The micropillar arrays, which was defined as islands, was made up of micropillars with diameter d, pitch 1 and height $\mathrm{h}$ as shown in Fig. 2(c). To apply heat to the evaporator samples and measure its temperature, thin film Pt heaters and resistance-temperature-detectors (RTDs) were created on the backside of the sample. Since the resistance of Pt films increase linearly with temperature, thus temperature of the sample backside can be calculated based on the resistance measurements of the RTDs. To conduct parametric study, samples with different microchannel sizes were fabricated. Sample geometries are listed in Table 1 with SEM measured geometric sizes. 
(a)

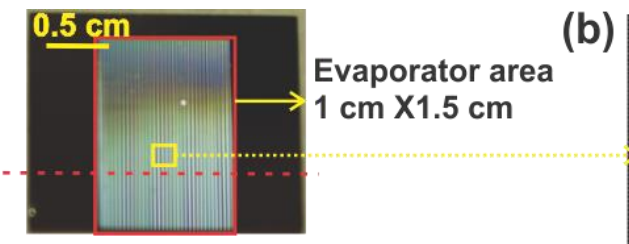

(c)

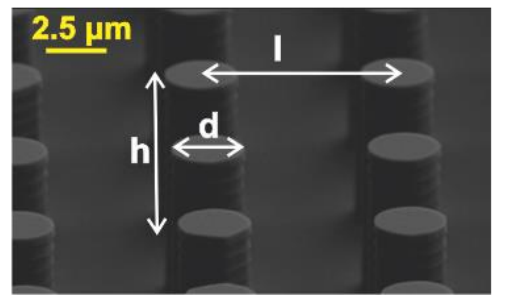

(b) $100 \mu \mathrm{m}$

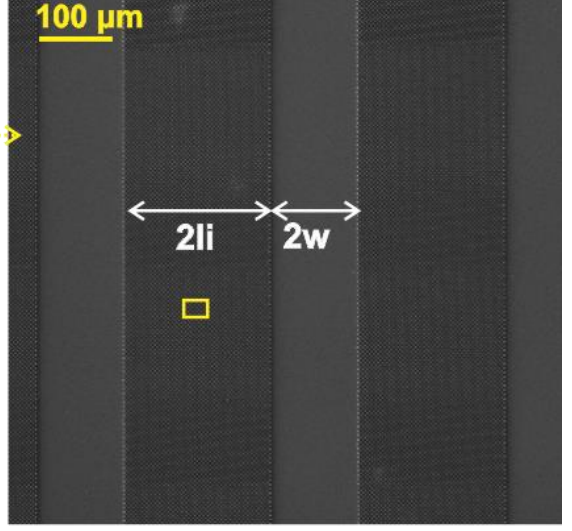

Fig. 2: (a) Image of biporous evaporator wick with size of $1 \mathrm{~cm} \times 1.5 \mathrm{~cm}$, in which $1 \mathrm{~cm}^{2}$ was used for thin film evaporation (b) SEM images of biporous evaporator with micropillar island size of $2 l_{i}$ and microchannel size of $2 w$ (b) SEM image of micropillars with diameter $d$, pitch $l$ and height $h$.

Table 1: List of Samples.

\begin{tabular}{|r|r|r|r|r|c|}
\hline Sample & $\boldsymbol{d}(\boldsymbol{\mu m})$ & $\boldsymbol{h}(\boldsymbol{\mu m})$ & $\boldsymbol{l}(\boldsymbol{\mu m})$ & $\boldsymbol{l}_{\boldsymbol{i}}(\boldsymbol{\mu m})$ & $\boldsymbol{w}(\boldsymbol{\mu m})$ \\
\hline $\mathbf{A}$ & 3.4 & 8.9 & 6 & 101 & 30 \\
\hline $\mathbf{B}$ & 3.4 & 8.9 & 6 & 101 & 58.5 \\
\hline $\mathbf{C}$ & 3.4 & 8.9 & 6 & 101 & 75 \\
\hline
\end{tabular}

\subsection{Thermal Characterization}

Prior to the thermal characterization, evaporator samples were cleaned with acetone, isopropanol (IPA) and DI water followed by 15 mins plasma cleaning using plasma cleaner (Harrick Plasma, PDC-002). Purpose of the cleaning process was to remove any dirt or contaminants that may reduce the wettability and performance of the samples. After cleaning, samples were mounted onto a printed circuit board (PCB) which was connected to the data acquisition system (Keysight 34970a). Experimental setup for thermal characterization was shown in Fig. 3. Then the PCB with the sample was kept in a vacuum chamber with controlled vacuum condition at around $5 \times 10^{-5}$ mbar to remove any non-condensable gas. Degassed DI water was used as working fluid, while degassing was done in the degassing tank through 3 repeating cycles of freeze-pump-thaw process. After that degassed DI water was filled into the liquid reservoir. This was to simulate the actual working condition inside a vapor chamber. Sample was held vertically to avoid flooding of evaporator surface. One flange of the vacuum chamber was cooled by the chiller to act as the condenser during the experiment. Heat was applied from the power supply to the heater to heat up the evaporator sample. There was a gradual increment of the applied power, the resistance readings of the RTDs were recorded when the readings was steady at each power value. Surface of the evaporator was monitored by a high speed camera. Once a dryout area was observed on the evaporator surface, the applied power was recorded as dryout heat flux. To transfer the resistance readings of RTD into temperature measurements of the sample, the correlation between RTD resistance and temperature was obtained. This was achieved through calibration of RTDs against a high precision Pt 100 thermometer (Omega). PCB with the evaporator sample was kept in the oven (OMH60, Heratherm) with gradual increment of temperature. Started from $30{ }^{\circ} \mathrm{C}$, the resistance readings of RTDs were recorded and averaged with each temperature increment of $5{ }^{\circ} \mathrm{C}$ to a upper temperature limit of $80{ }^{\circ} \mathrm{C}$. Data collection was done when the temperature readings reached a steady state value, which usually took $20 \mathrm{mins}$. Then the linear relationship between temperature and RTD resistance was fitted with an expression of $T_{\text {sensor }}=a R+b$. With this equation, the corresponding temperatures of sample back side can be calculated with the averaged resistance readings. Temperature of micropillar bottom was calculated by assuming a 1D conduction across the oxide layer and silicon substrate,

$$
\Delta T=T_{\text {sensor }}-q^{\prime \prime}\left(\frac{t_{\text {wafer }}-h-t_{\mathrm{SiO}_{2}}}{k_{\mathrm{Si}}}+\frac{t_{\mathrm{SiO}_{2}}}{k_{\mathrm{SiO}_{2}}}\right)-T_{\text {ambient }}
$$


Heat flux dissipated was obtained by subtracting the applied heat flux by the heat flux dissipated due to heat loss.

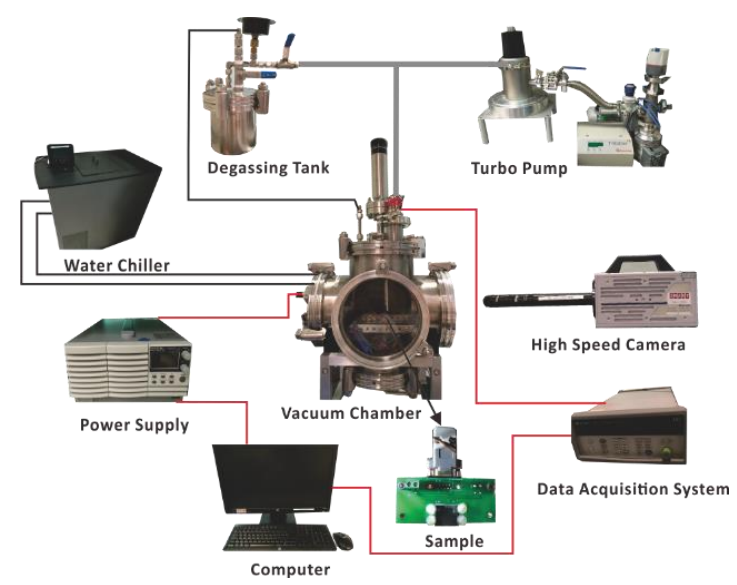

Fig. 3: Thermal characterization experimental setup (not in scale): sample was mounted onto a PCB and kept inside a vacuum chamber. Heat was applied from power supply to the heater and resistance readings of RTDs were recorded by data acquisition system. Sample surface was monitored by high speed camera to determine the dryout point.

\section{Results and Discussion}

Results for thermal characterization were plotted in Fig. 4 as heat flux vs. superheat curves. Heat flux applied to the sample was calculated as the voltage applied to the sample times the current flowed through the sample. Heat flux dissipated by the sample was obtained by calibrating the bare sample with heat loss test. Superheat was defined as the temperature difference between micropillar bottom and the ambient. Observed dryout heat flux of each sample was indicated by the arrows. According to Fig. 4, dryout heat fluxes for sample A, B, C were $23.4 \mathrm{~W} / \mathrm{cm} 2,55.9 \mathrm{~W} / \mathrm{cm} 2$ and $39.5 \mathrm{~W} / \mathrm{cm} 2$ respectively. Sample B was observed to perform best among all the three samples in terms of its highest dryout heat flux. Sample A has a narrower microchannel compared with sample B, which also corresponded to a higher pressure drop inside the microchannel. Thus the dryout heat flux of sample A was lower than that of sample B. For sample $\mathrm{C}$, although the microchannel width was larger and pressure drop was lower than that of sample B, wider microchannels also resultant in decrease of evaporation areas. Thus sample C dried earlier than sample B. Sample B possess an optimal balance between the pressure drop and available thin film evaporation areas. Therefore the sample B performed best among the samples with different geometries. The model predicted dryout heat flux for sample B was $62.0 \mathrm{~W} / \mathrm{cm} 2$ according to Eq. (1). The difference between model predicted dryout heat flux and experimental measured dryout heat flux was only $9.0 \%$, which indicated the accuracy of the model. Model was found to overestimate the dryout heat flux, this was due to the over prediction of capillary pressure based on Xiao et. al.'s model[15] as discussed in [17].

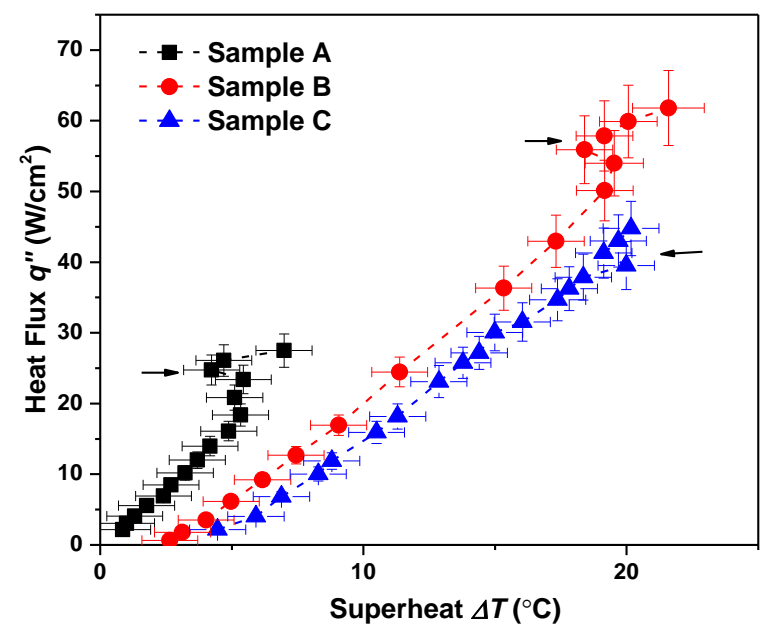

Fig. 4: Thermal characterization results ( $q$ "' vs. $\Delta T$ ) for sample A, B and C. The dryout heat flux are indicated by the arrow. 


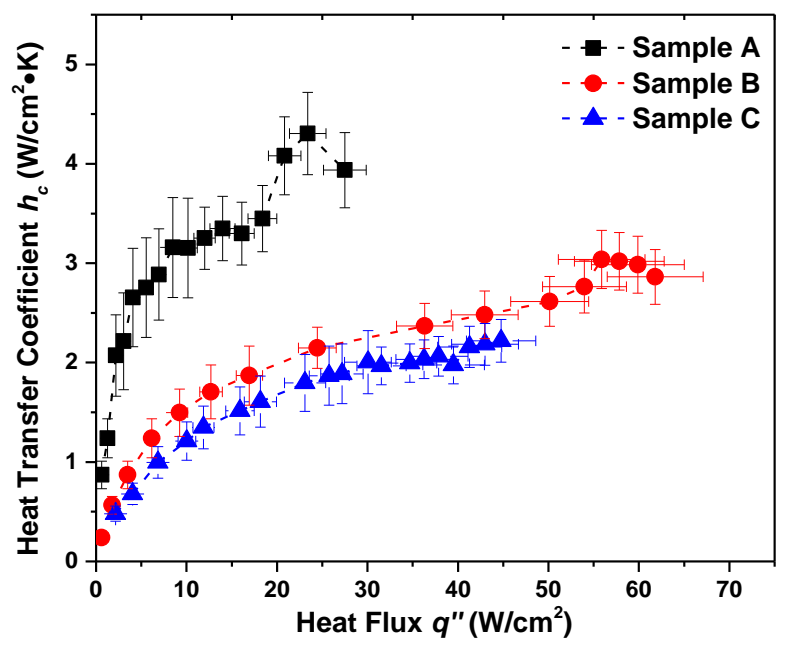

Fig. 5: Heat transfer coefficient $h_{c}$ vs. heat flux $q$ '” curves for sample A, B and C.

According to Fig. 4, the temperature difference $(\Delta T)$ was lower for samples with narrower microchannels. This is attributed to the larger island size and more thin film evaporation areas for sample with narrower microchannels. The meniscus around micropillars can be divided into intrinsic meniscus region, thin film evaporation region and nonevaporation region along the distance away from the micropillar sidewalls [18]. The thin film evaporation occupied only $20 \%$ of total meniscus area, but account for more than $80 \%$ of total heat transfer. With more evaporator area covered by micropillars, the number of micropillars and so as the thin film evaporation regions will be larger. Thus the heat transfer due to thin film evaporation will be more effective. Which resulted in a lower sample temperature.

Heat transfer coefficient versus heat flux curve for sample A, B and C was plotted in Figure 5. It can be observed from Figure 5 that the heat transfer coefficient increased with heat flux before dryout. This can be explained by the increase of liquid meniscus curvature as heat flux increase. Prior to dryout, as heat flux increased, the liquid evaporation rate increased. As liquid meniscus was pinned by the top of micropillars, meniscus curvature increased and resulted in more thin film evaporation areas. This led to the enhancement in heat transfer coefficient. After the inception of dryout, heat transfer coefficient decreased slightly, which was attributed to less area covered by liquid. The decrease of heat transfer coefficient and increase of temperature was not as abrupt as that for uniform evaporators in our previous study [10]. This was due to the existence of microchannels that acted as local liquid reservoir to prevent rapid expanding of dry area after dryout.

\section{Conclusions}

In this paper, silicon micropillar based biporous evaporators with microchannel structures were fabricated and thermally tested. Evaporators were fabricated by standard Micro-Electro-Mechanical Systems (MEMS) process with evaporator wicks on the front side of the sample, and Pt heater and RTDs on the backside. The samples were tested inside a vacuum chamber. A highest heat flux of $55.9 \mathrm{~W} / \mathrm{cm}^{2}$ was demonstrated by the sample B. A deviation of only $9.0 \%$ between the model predicted and experimental measured dryout heat flux validated the model with high accuracy. Samples with wider channel were shown to have higher superheat due to less evaporation areas. The biporous evaporator was proven to perform much better than uniform evaporation due to the existence of microchannel that served as local liquid reservoir to supply liquid, which delayed the expansion of dry areas after dryout. This paper provided a comprehensive study of silicon micropillar based biporous evaporators and can serve as useful design guidance for evaporators that can be used in advanced vapor chambers.

\section{Acknowledgements}

Funding support from National Research Foundation Singapore and Singapore-MIT Alliance for Research and Technology's Low Energy Electronic Systems (LEES) IRG are gratefully acknowledged. 


\section{References}

[1] B. He, M. Wei, S. Somasundaram, C. S. Tan, and E. N. Wang, "Experiments on the ultrathin silicon vapor chamber for enhanced heat transfer performance," in 2016 15th IEEE Intersociety Conference on Thermal and Thermomechanical Phenomena in Electronic Systems (ITherm), pp. 569-573, 2016.

[2] C. Qingjun, C. Bing-chung, and T. Chialun, "Design, development and tests of high-performance silicon vapor chamber," Journal of Micromechanics and Microengineering, vol. 22, p. 035009, 2012.

[3] X. Cao, P. Cheng, and T. Zhao, "Experimental study of evaporative heat transfer in sintered copper bidispersed wick structures," Journal of thermophysics and heat transfer, vol. 16, pp. 547-552, 2002.

[4] T. Semenic, Y. Y. Lin, I. Catton, and D. B. Sarraf, "Use of biporous wicks to remove high heat fluxes," Applied Thermal Engineering, vol. 28, pp. 278-283, 2008.

[5] T. Semenic, Y.-Y. Lin, and I. Catton, "Thermophysical properties of biporous heat pipe evaporators," Journal of Heat Transfer, vol. 130, p. 022602, 2008.

[6] T. Semenic and I. Catton, "Experimental study of biporous wicks for high heat flux applications," International Journal of Heat and Mass Transfer, vol. 52, pp. 5113-5121, 2009.

[7] T. Semenic, Y.-Y. Lin, and I. Catton, "Biporous sintered copper for closed loop heat pipe evaporator," in ASME 2005 International Mechanical Engineering Congress and Exposition, pp. 21-25, 2005.

[8] C. Byon and S. J. Kim, "Capillary performance of bi-porous sintered metal wicks," International Journal of Heat and Mass Transfer, vol. 55, pp. 4096-4103, 2012.

[9] M. Wei, S. Somasundaram, B. He, Q. Liang, R. Raj, C. S. Tan, et al., "Optimization of Biporous Micropillar Array for Enhanced Heat Transfer Performance," in ASME 2015 International Mechanical Engineering Congress and Exposition, pp. V08BT10A002-V08BT10A002, 2015.

[10] M. Wei, B. He, S. Somasundaram, C. S. Tan, and E. N. Wang, "Optimization and thermal characterization of uniform micropillar based silicon evaporator in advanced vapor chambers," in 2016 15th IEEE Intersociety Conference on Thermal and Thermomechanical Phenomena in Electronic Systems (ITherm), pp. 1019-1023, 2016.

[11] M. Wei, S. Somasundaram, B. He, Q. Liang, C. S. Tan, and E. N. Wang, "Experimental characterization of Si micropillar based evaporator for advanced vapor chambers," in Electronics Packaging Technology Conference (EPTC), 2014 IEEE 16th, pp. 335-340, 2014.

[12] C. Byon and S. J. Kim, "Study on the capillary performance of micro-post wicks with non-homogeneous configurations," International Journal of Heat and Mass Transfer, vol. 68, pp. 415-421, 2014.

[13] S. Ravi, R. Dharmarajan, and S. Moghaddam, "Physics of fluid transport in hybrid biporous capillary wicking microstructures," Langmuir, vol. 32, pp. 8289-8297, 2016.

[14] D. Ćoso, V. Srinivasan, M.-C. Lu, J.-Y. Chang, and A. Majumdar, "Enhanced heat transfer in biporous wicks in the thin liquid film evaporation and boiling regimes," Journal of Heat Transfer, vol. 134, p. 101501, 2012.

[15] R. Xiao, R. Enright, and E. N. Wang, "Prediction and optimization of liquid propagation in micropillar arrays," Langmuir, vol. 26, pp. 15070-15075, 2010.

[16] C. Byon and S. J. Kim, "The effect of meniscus on the permeability of micro-post arrays," Journal of Micromechanics and Microengineering, vol. 21, p. 115011, 2011.

[17] R. Xiao and E. N. Wang, "Microscale liquid dynamics and the effect on macroscale propagation in pillar arrays," Langmuir, vol. 27, pp. 10360-10364, 2011.

[18] R. Ranjan, J. Y. Murthy, and S. V. Garimella, "A microscale model for thin-film evaporation in capillary wick structures," International Journal of Heat and Mass Transfer, vol. 54, pp. 169-179, 2011. 